\title{
Expression of BDNF, TrkB, VEGF and CD105 is associated with pelvic lymph node metastasis and prognosis in IB2-stage squamous cell carcinoma
}

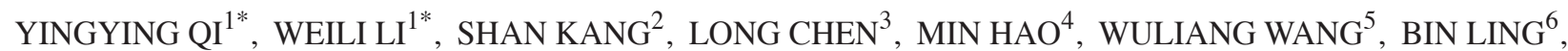

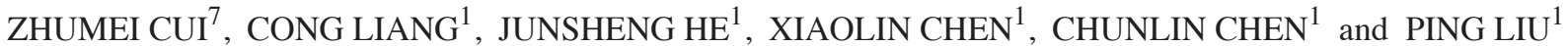

\begin{abstract}
${ }^{1}$ Department of Obstetrics and Gynecology, Nanfang Hospital, Southern Medical University, Guangzhou, Guangdong 510515;
${ }^{2}$ Department of Gynecology, Fourth Hospital, Hebei Medical University, Shijiazhuang, Hebei 050000; ${ }^{3}$ Department of

Gynecology, Qingdao Municipal Hospital, Qingdao, Shandong 266000; ${ }^{4}$ Department of Obstetrics and Gynecology,

The Second Hospital of Shanxi Medical University, Taiyuan, Shanxi 030000; ${ }^{5}$ Department of Obstetrics and Gynecology,

The Second Affiliated Hospital of Zhengzhou University, Zhengzhou, Henan 450000; ${ }^{6}$ Department of Obstetrics and

Gynecology, China-Japan Friendship Hospital, Beijing 100000; ${ }^{7}$ Department of Gynecology, The Affiliated Hospital of Qingdao University Medical College, Qingdao, Shandong 266000, P.R. China
\end{abstract}

Received February 18, 2019; Accepted August 15, 2019

DOI: $10.3892 / \mathrm{etm} .2019 .8100$

\begin{abstract}
Brain-derived neurotrophic factor (BDNF), tropomyosin receptor kinase B (TrkB), vascular endothelial growth factor (VEGF) and CD105 are highly expressed in several types of cancer. The present study aimed to determine whether BDNF, TrkB, VEGF and CD105 are associated with the prognosis and metastasis of patients with cervical squamous cell carcinoma (SCC) at the IB2 stage. A total of 79 patients with IB2-stage SCC were enrolled in the present study. The expression levels of BDNF, TrkB, VEGF and CD105 in IB2-stage cervical cancer tissue were detected by immunohistochemistry and their association with clinicopathological indexes or prognostic factors was statistically analyzed. Reverse transcription quantitative PCR was used to detect whether the expression of VEGF was affected in SiHa cells co-cultured with BDNF. In addition, BDNF-induced $\mathrm{SiHa}$ cell migration and invasion were examined. BDNF expression in the cervical cancer samples was significantly associated with positive lymphovascular space invasion $(\mathrm{P}<0.001)$ and pelvic lymph node metastasis $(\mathrm{P}<0.05)$. In
\end{abstract}

Correspondence to: Dr Chunlin Chen or Dr Ping Liu, Department of Obstetrics and Gynecology, Nanfang Hospital, Southern Medical University, 1,838 Guangzhou North Avenue, Guangzhou, Guangdong 510515, P.R. China

E-mail: ccl1@smu.edu.cn

E-mail: 1pivy@126.com

*Contributed equally

Key words: brain-derived neurotrophic factor, tropomyosin receptor kinase B, vascular endothelial growth factor, CD105, pelvic lymph node metastasis, squamous cell carcinoma addition, microvessel density was verified as an independent prognostic factor for overall survival $(\mathrm{P}<0.05)$. In vitro analysis indicated that BDNF significantly induced cellular migration and invasion of $\mathrm{SiHa}$ cells in a dose-dependent manner $(\mathrm{P}<0.001)$. BDNF induced the expression of VEGF in $\mathrm{SiHa}$ cells, which was inhibited by BDNF antibodies or an inhibitor of TrkB receptor $(\mathrm{P}<0.05)$. BDNF may be considered a useful indicator of pelvic metastasis, which is involved in the aggressive spread of IB2-stage SCC. BDNF-induced upregulation of VEGF was revealed to act as a pro-angiogenic factor in SCC (Trial registration no. http://apps.who. int/trialsearch/; ChiCTR1800017778).

\section{Introduction}

Cervical cancer is a common cancer type in females. Approximately 132,000 novel cases of cervical cancer are reported each year in China, accounting for $28 \%$ of the total number of cases worldwide. Furthermore, an increasing proportion of females $<35$ years old have developed cervical cancer in the past 5 years in China (1). The tumor microenvironment (comprising tumor cells, nerves and blood vessels), inflammatory cells and cytokines are closely linked to the origin and progression of tumors (2). Chen (3) revealed that nerve fibers and neurotrophins in the tumor microenvironment are associated with the progression of cervical cancer and the proportion of new nerves in cervical cancer was higher than that in the normal cervix (3). In addition, brain-derived neurotrophic factor (BDNF) and tropomyosin receptor kinase $\mathrm{B}$ (TrkB) were indicated to be widely expressed in cervical cancer. The TrkB expression level in cervical squamous cell carcinomas (SCC) was reported to be higher than that in the normal cervix. Furthermore, TrkB-positive vessels have been observed in foci of SCC (4). BDNF, a cytokine detected in a series of non-neurogenic tumors, belongs to the neurotrophin 
family and has been indicated to be involved in tumor cell proliferation and invasion $(2,5-7)$; it also induces perineural invasion (8-10).

The probability of recurrence and metastasis of SCC at the IB2 stage (also known as bulky-stage SCC) is much higher than at the early stage of cervical cancer. Furthermore, the prognosis of IB2-stage SCC is less favorable $(11,12)$. However, to date, no biomarkers to accurately and effectively predict the recurrence and metastasis potential of cervical cancer at the bulky stage have been identified. Of note, the serum level of SSC antigen (SccA) reportedly is associated with the tumor grade, size and interstitial infiltration of cervical cancer; however, it only increased in $65 \%$ of patients with cervical cancers vs. normal volunteers, while serum level of cancer antigen 125 (CA125) was reported to increase in only $15 \%$ patients with cervical adenocarcinoma (13).

The role of the BDNF-TrkB regulatory system in SCC remains to be fully elucidated. In the present study, it was hypothesized that the potential for metastasis and recurrence of IB2-stage SCC is associated with the expression levels of BDNF and TrkB. Thus, data from clinical trials were retrospectively studied to investigate whether the expression of BDNF and TrkB, as well as other associated factors, is associated with the prognosis and metastasis of IB2-stage SCC. The SiHa cell line is a human papillomavirus 16-positive cervical cancer cell line, which has the characteristics of cervical SSC. In order to explore the role of BDNF in the progression of SCC, a Transwell assay was applied to evaluate the effect of BDNF on the migration and invasion in SiHa cells. The aim of the present study was to discover a biomarker that may serve as a predictor of progression of bulky-stage SCC and explore whether BDNF and its receptors are involved in the angiogenesis of SCC.

\section{Materials and methods}

Patients. A total of 79 IB2-stage SCC patients treated between January 2006 and December 2012 at the Department of Obstetrics and Gynecology of Nanfang Hospital (affiliated to Southern Medical University, Guangzhou, China) were enrolled in the present study. The diagnoses of all SCC patients enrolled were performed based on the post-operative pathological results. The general and clinical information of the SCC patients was collected, including age, sex, gestation, parity, Fédération Internationale de Gynécologie et d'Obstétrique stage, pre-operative hemoglobin level, duration of operation, type of surgery, complications, lymphovascular space involvement (LVSI) status, depth of cervical infiltration, uterine body invasion, parametrical infiltration, pelvic lymph node status and post-operative therapy. The clinical and pathological data of the patients were entered into Epidata software 3.1 version (The EpiData Association) separately by two gynecologists, who revised the date together, to ensure input errors were minimized. In order to compare the expression levels of BDNF, TrkB, vascular endothelial growth factor (VEGF) and CD105 between cervical cancer tissue and normal cervix tissue, samples of normal comparable cervix tissue $(n=10)$ were obtained from uterine leiomyoma patients who underwent a hysterectomy in the same time period as patients in the cervical cancer cohort at the Department of Obstetrics and Gynecology of Nanfang Hospital.
Ethics approval and informed consent. This study was part of a clinical research project based on a multicenter study of cervical cancer in China. It was approved by the Ethics Committee of Nanfang Hospital, Southern Medical University (Guangzhou, China; code: NEEC-2017-135). Written informed consent for the use of specimens for scientific research was provided by all patients included in the current study.

Cell culture. SiHa cells purchased from American Type Culture Collection were provided by the laboratory at Southern Medical University and incubated with complete Dulbecco's modified Eagle's medium (DMEM; Gibco; Thermo Fisher Scientific, Inc.) containing 10\% fetal bovine serum (Gibco; Thermo Fisher Scientific, Inc.) and $1 \%$ penicillin-streptomycin (Thermo Fisher Scientific, Inc.) in an incubator at $37^{\circ} \mathrm{C}$ with $5 \%$ $\mathrm{CO}_{2}$. For stimulation with BDNF (recombinant human BDNF; cat. no. 450-1; PeproTech EC, Ltd.), the SiHa cells starved for $12 \mathrm{~h}$ and incubated with serum-free DMEM supplemented with 20,50 or $100 \mathrm{ng} / \mathrm{ml} \mathrm{BNDF}$ for $18 \mathrm{~h}$. In another test to neutralize the effect of BDNF, the SiHa cells were divided into three groups: The $100 \mathrm{ng} / \mathrm{ml}$ BDNF group, the BDNF (100 ng/ml) plus BDNF antibody (1:500; cat. no. 500-P84; PeproTech) group, and BDNF (100 ng/ml) plus TrkB inhibitor ANA12 (1 mg/ml; BioVision, Inc.) group. SiHa cells cultured in DMEM were used as the control group.

Immunohistochemical staining. The cervical tissue specimens were taken from surgically cut tissue from the SCC patients and the uterine leiomyoma patients, embedded in paraffin, cut into 4- $\mu \mathrm{m}$ thick sections, placed on glass slides and incubated for $10 \mathrm{~min}$ in $3 \% \mathrm{H}_{2} \mathrm{O}_{2}$ at room temperature to inhibit endogenous peroxidases. The slides were then incubated with 3,3-diaminobenzidine (DAB) for 10 min, washed with PBS, stained with $10 \%$ hematoxylin, dehydration with gradient ethanol. After washing with PBS, the samples were blocked by incubation with $5 \%$ goat serum (cat. no. ab 138478; Abcam) at room temperature for $10 \mathrm{~min}$. The primary antibody reaction was performed at $4^{\circ} \mathrm{C}$ overnight in $1 \%$ goat serum in PBS containing the corresponding antibody [BDNF (1:500; cat. no. ab203573; Abcam), TrkB (1:500; cat. no. SC-8316; Santa Cruz Biotechnology, Inc.), VEGF (1:250; cat. no. ab32152; Abcam), CD105 (1:500; cat. no. ab135528; Abcam) and PBS (as the negative control)]. After triple washing with PBS, the slides were incubated with the secondary antibody (Goat Anti-Mouse Anti-Rabbit IgG/IgM H\&L; 1:100; cat. no. ab2891; Abcam) for $30 \mathrm{~min}$ at room temperature.

Average optical density (IOD) and microvessel density (MVD) evaluation. The images were captured on a Nikon Bx51 camera (Nikon Corporation). DAB-stained regions of interest were defined based on their immunohistochemical staining profiles in in a constant manner. To analyze the immunohistochemically stained slides, 10 fields of the target slide at a magnification of x400 were captured and the average integrated optical density (IOD) was analyzed with Image Pro Plus v6.0 software (Media Cybernetics, Inc.). Microvessel density (MVD) was determined by immunostaining for CD105 according to Weidner's method (14). In brief, single brown-stained endothelial cell or clusters of brown-stained endothelium (with or without lumen) were counted as individual vessels. The slides were screened at a magnification of x100-200 under an upright microscope to 


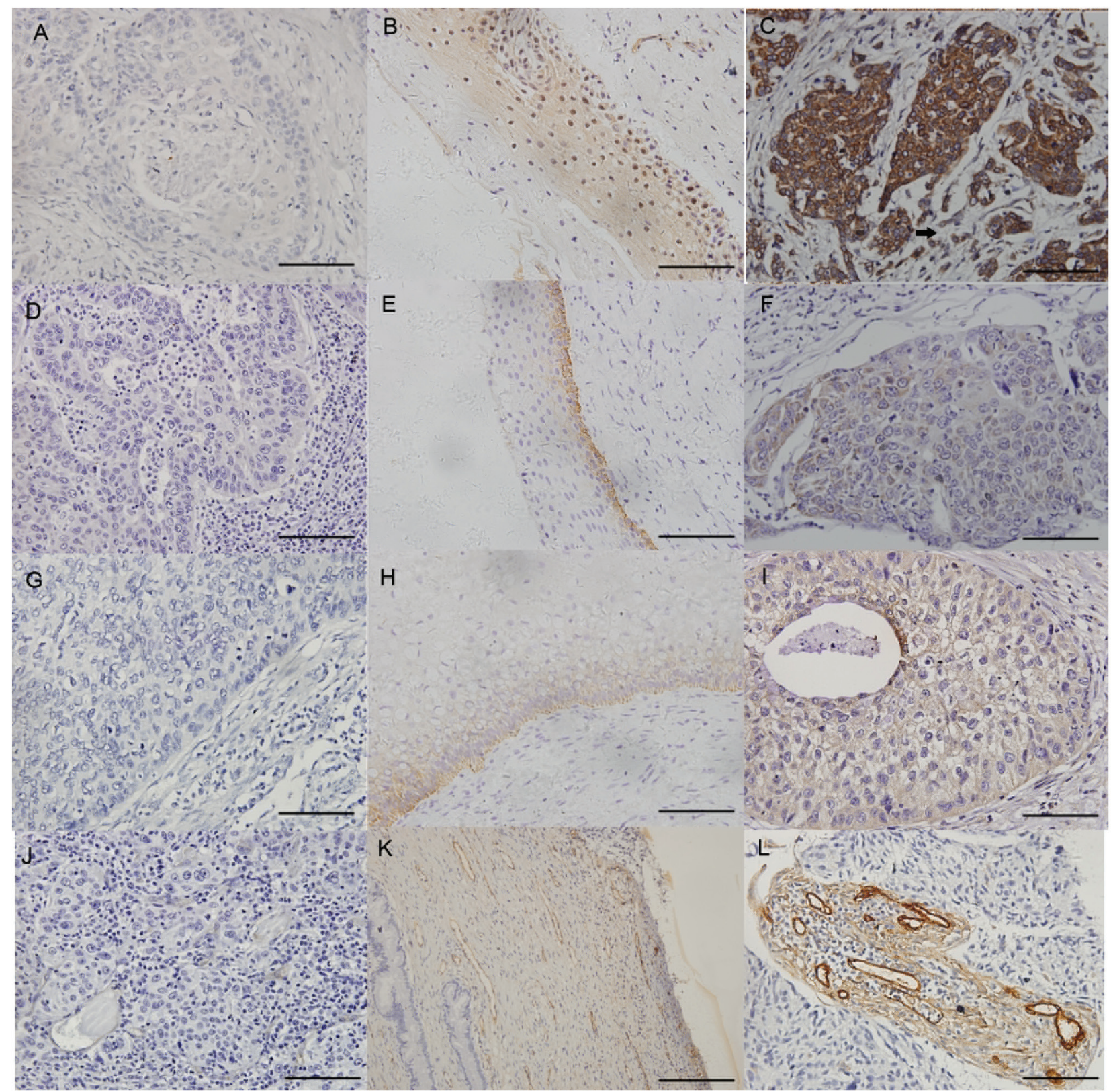

Figure 1. Immunohistochemical staining for BDNF, TrkB, VEGF and CD105 in cervical cancer specimens. The expression of (A-C) BDNF, (D-F) TrkB, (G-I) VEGF and (J-L) CD105 was detected by immunohistochemical staining in negative controls, normal cervical epithelium and cervical cancer specimens, respectively, from left to right. Negative controls were incubated with PBS only instead of primary antibody. The scale bar was $50 \mu \mathrm{m}$ in A-I and $100 \mu \mathrm{m}$ in $\mathrm{J}-\mathrm{L}$. The arrow in $\mathrm{C}$ indicates negative staining for BDNF in the cervical cancer stroma. BDNF, brain-derived neurotrophic factor; TrkB, tropomyosin receptor kinase B; VEGF, vascular endothelial growth factor.

determine the field of the target area containing large number of positive vessels. Three fields at the magnification of $x 400$ that had the highest concentrations of microvessels were selected and the number of microvessels was counted. The mean value of the three fields was taken as the mean MVD.

Transwell migration and invasion assay. The migration and invasion capacity of SiHa cells were determined using Transwell plates for 24 -well plates $(6.5 \mathrm{~mm}$; pore size $8 \mu \mathrm{m}$; Corning, Inc.) according to the manufacturer's protocol. For the cellular migration assay, the pre-treated SiHa cells were suspended in $600 \mu \mathrm{l}$ serum-free DMEM at a density of $10^{5}$ cells $/ \mathrm{ml}$ and seeded into the upper chambers of Transwell plates; $100 \mu 1$ of serum-free DMEM was supplied into the lower chamber. After $24 \mathrm{~h}$ of incubation at $37^{\circ} \mathrm{C}$, the migrated tumor cells on the lower side of the filter were fixed with $4 \%$ paraformaldehyde and stained with crystal violet (Ubio).

For the cellular invasion assay, the procedure was similar to that described above, except that the inserted filter was pre-coated with Matrigel (BD Biosciences; diluted at 1:6) and the plates were incubated for $24 \mathrm{~h}$ at $37^{\circ} \mathrm{C}$.

The migrated and invaded cells were counted in triplicate fields of view three times under an Olympus CKX41 inverted microscope (Olympus Corporation) at a magnification of x100.

Western blot analysis. The treated cells were lysed with radioimmunoprecipitation assay protein lysis buffer (containing protease inhibitors) and centrifuged at $12,000 \mathrm{x} \mathrm{g}$ or $4 \mathrm{~min}$ at 
Table I. Analysis of the association between BDNF and TrkB with clinicopathological indexes of IB2-stage cervical differentiated squamous cell carcinoma.

\begin{tabular}{|c|c|c|c|c|c|c|}
\hline \multirow[b]{2}{*}{ Characteristic } & \multicolumn{3}{|c|}{ BDNF } & \multicolumn{3}{|c|}{ TrkB } \\
\hline & $\mathrm{N}$ & Mean \pm SD & P-value & $\mathrm{N}$ & Mean \pm SD & P-value \\
\hline \multicolumn{7}{|l|}{ Age (year) } \\
\hline$\leq 35$ & 5 & $0.06 \pm 0.03$ & 0.978 & 5 & $0.01 \pm 0.01$ & 0.068 \\
\hline$>35$ or $\leq 50$ & 48 & $0.06 \pm 0.04$ & & 44 & $0.03 \pm 0.03$ & \\
\hline$>50$ & 26 & $0.07 \pm 0.03$ & & 26 & $0.02 \pm 0.02$ & \\
\hline Tumor diameter $(\mathrm{cm})$ & & & 0.209 & & & 0.425 \\
\hline$>4,<5$ & 40 & $0.06 \pm 0.04$ & & 37 & $0.02 \pm 0.02$ & \\
\hline$\geq 5$ & 39 & $0.07 \pm 0.04$ & & 38 & $0.03 \pm 0.03$ & \\
\hline Gross type & & & 0.046 & & & 0.249 \\
\hline Exogenous & 63 & $0.07 \pm 0.04$ & & 59 & $0.02 \pm 0.02$ & \\
\hline Ulcerative & 11 & $0.05 \pm 0.02$ & & 11 & $0.03 \pm 0.02$ & \\
\hline DSI & & & 0.188 & & & 0.441 \\
\hline No & 33 & $0.06 \pm 0.03$ & & 31 & $0.03 \pm 0.02$ & \\
\hline Yes & 44 & $0.07 \pm 0.04$ & & 42 & $0.02 \pm 0.02$ & \\
\hline LVSI & & & 0.001 & & & 0.256 \\
\hline Yes & 13 & $0.09 \pm 0.04$ & & 11 & $0.04 \pm 0.04$ & \\
\hline No & 66 & $0.06 \pm 0.03$ & & 64 & $0.02 \pm 0.02$ & \\
\hline Pelvic lymph node metastasis & & & 0.010 & & & 0.202 \\
\hline No & 56 & $0.06 \pm 0.03$ & & 54 & $0.02 \pm 0.02$ & \\
\hline Yes & 23 & $0.08 \pm 0.04$ & & 21 & $0.03 \pm 0.03$ & \\
\hline
\end{tabular}

DSI, deep stromal invasion; LVSI, lymphovascular space invasion; BDNF, brain-derived neurotrophic factor; TrkB, tropomyosin receptor kinase $\mathrm{B} ; \mathrm{SD}$, standard deviation.

$4^{\circ} \mathrm{C}$. The protein concentration of the supernatant was detected with a bicinchoninic acid assay kit (BioVision). A total of $40 \mathrm{mg}$ of the total protein samples were loaded onto $12 \%$ SDS-PAGE gel, separated by electrophoresis and transferred onto a polyvinylidene difluoride membrane (Sigma-Aldrich; Merck KGaA). The membranes were blocked with Tris-buffered saline containing 5\% skimmed milk for $1 \mathrm{~h}$, incubated with VEGF antibody (1:500; cat. no. 251622; ZEN-Biotech) overnight at $4^{\circ} \mathrm{C}$, triple-washed with Tris-buffered saline containing Tween-20, reacted with secondary antibody (1:500; cat. no. 220173; ZEN-Biotech Pvt. Ltd.) at room temperature for $1 \mathrm{~h}$, triple washed again, and visualized using an enhanced chemiluminescence detection kit (GE Healthcare). The protein bands were then exposed to X-ray film (Fujifilm).

Reverse transcription quantitative PCR ( $q P C R)$. Total RNA was extracted with an RNA Extraction kit (Promega Corp.), The reaction mix contained $175 \mu \mathrm{l}$ of RNA polymerase, $300 \mathrm{nM}$ of primer and $100 \mathrm{ng}$ of RNA. The RNA was amplified with a starting denaturation for $10 \mathrm{~min}$ at $95^{\circ} \mathrm{C}, 95^{\circ} \mathrm{C}$ for $30 \mathrm{sec}$, $56^{\circ} \mathrm{C}$ for $60 \mathrm{sec}$, and $72^{\circ} \mathrm{C}$ for $60 \mathrm{sec}$, and was repeated for 40 cycles. The PCR mixture was prepared with SYBR Green PCR Master Mix (Toyobo), according to the manufacturer's protocol. 18srRNA (15) was used as the endogenous reference gene for qPCR analysis. Each reaction was performed in triplicate. The results were analyzed using the $2^{-\Delta \Delta C q}$ method (16).
The primers used for qPCR were as follows: VEGF forward, 5'-GCAGATTATGCGGATCAAACC-3' and reverse, 5'-TTT CGTTTTTGCCCCTTTCC-3'; endogenous reference forward, 5'-CCTGGATACCGCAGCTAGGA-3'; and reverse, 5'-GCG GCGCAATACGAATGCCCC-3'.

Statistical analysis. SPSS v21.0 software (IBM Corp.) was employed for statistical analysis. Values are expressed as the mean \pm the standard deviation or standard error. A Student's t-test was applied to evaluate the differences between two groups. Statistical analysis of multiple groups was performed using one-way analysis of variance, followed by Dunnett's test. The $\chi^{2}$-square test was used to analyze categorical variables. The univariate analysis of the association of factors with survival were performed using one-way ANOVA and Student's t-test, for categorical variables and continuous variables respectively. The Cox proportional hazards model was employed to assess the association of a variety of factors with survival. Survival curves were plotted using the Kaplan-Meier method. $\mathrm{P}<0.05$ was considered to indicate statistical significance.

\section{Results}

SCC patients. The average age of the 79 SCC patients was $47.84 \pm 8.46$ years (range, $24-68$ years). The follow-up period 
Table II. Analysis of the association of VEGF and MVD with clinicopathological characteristics of IB2-stage cervical squamous cell carcinoma.

\begin{tabular}{|c|c|c|c|c|c|c|}
\hline \multirow[b]{2}{*}{ Characteristic } & \multicolumn{3}{|c|}{ MVD } & \multicolumn{3}{|c|}{ VEGF } \\
\hline & $\mathrm{N}$ & Mean \pm SD & P-value & $\mathrm{N}$ & Mean \pm SD & P-value \\
\hline \multicolumn{7}{|l|}{ Age (year) } \\
\hline$\leq 35$ & 7 & $11.76 \pm 2.81$ & 0.878 & 11 & $0.78 \pm 0.05$ & 0.567 \\
\hline$>35$ or $\leq 50$ & 43 & $12.11 \pm 2.71$ & & 34 & $0.08 \pm 0.03$ & \\
\hline$>50$ & 25 & $10.90 \pm 2.71$ & & 30 & $0.08 \pm 0.01$ & \\
\hline Tumor diameter $(\mathrm{cm})$ & & & 0.463 & & & 0.006 \\
\hline$>4,<5$ & 37 & $11.84 \pm 2.89$ & & 40 & $0.06 \pm 0.05$ & \\
\hline$\geq 5$ & 38 & $12.31 \pm 2.60$ & & 39 & $0.09 \pm 0.06$ & \\
\hline Gross type & & & 0.381 & & & 0.412 \\
\hline Exogenous & 59 & $11.79 \pm 2.67$ & & 63 & $0.07 \pm 0.06$ & \\
\hline Ulcerative & 11 & $12.57 \pm 2.90$ & & 11 & $0.08 \pm 0.05$ & \\
\hline DSI & & & 0.862 & & & 0.852 \\
\hline No & 31 & $11.99 \pm 2.86$ & & 33 & $0.07 \pm 0.05$ & \\
\hline Yes & 42 & $12.10 \pm 2.60$ & & 44 & $0.07 \pm 0.06$ & \\
\hline LVSI & & & 0.695 & & & 0.005 \\
\hline Yes & 12 & $12.36 \pm 1.83$ & & 13 & $0.11 \pm 0.04$ & \\
\hline No & 63 & $12.02 \pm 2.88$ & & 66 & $0.06 \pm 0.05$ & \\
\hline Pelvic lymph node metastasis & & & 0.403 & & & 0.222 \\
\hline No & 54 & $12.24 \pm 2.94$ & & 56 & $0.07 \pm 0.06$ & \\
\hline Yes & 21 & $11.65 \pm 2.10$ & & 23 & $0.08 \pm 0.05$ & \\
\hline
\end{tabular}

DSI, deep stromal invasion; LVSI, lymphovascular space invasion; SD, standard deviation; MVD, microvessel density; VEGF, vascular endothelial growth factor.

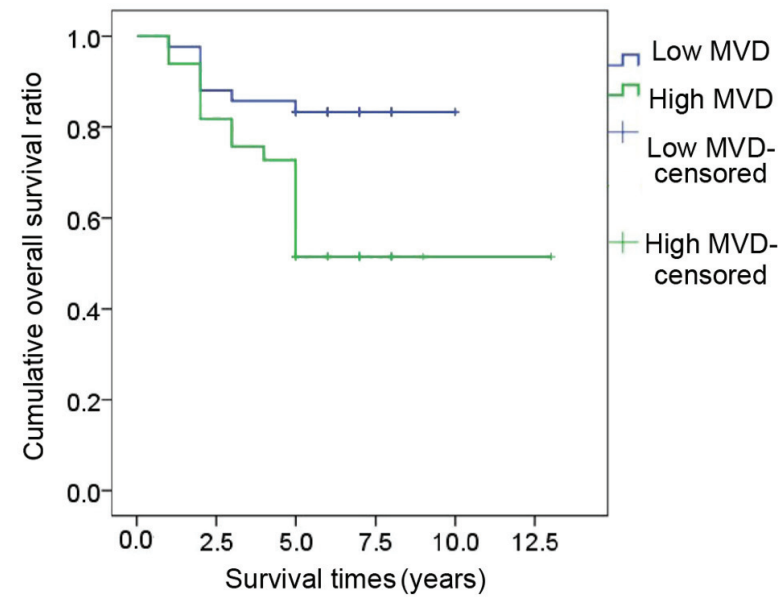

Figure 2. Kaplan-Meier analysis of the association between MVD and survival. An analysis of the associative link between the MVD and survival (MVD-) in patients with low CD105 (blue) or higher CD105 (green) levels is provided (cutoff value: 12.2). High MVD is an independent prognostic factor for OS. MVD, micro-vessel density.

after surgical resection ranged from 1 to 13 years (average, $5.9 \pm 2.0$ years). During the follow-up, 23 patients died. Additional information on the cohort is listed in Supplemental Table SI.
Expression and location of BDNF, TrkB, VEGF and CD105 in IB2-stage cervical SCC tissue according to immunochemical staining. The protein expression of BDNF, TrkB, VEGF and CD105 in the cervical cancer tissue specimens and the normal cervix samples was evaluated by immunochemical staining with the corresponding antibodies. BDNF, TrkB and VEGF were identified to be widely expressed in the tumor cells with positive rates of $97.6,88.2$ and $93.0 \%$, respectively. CD105 was located in the capillary wall with a positive rate of $92.4 \%$. TrkB and VEGF were also detected in the capillary walls of the cancer specimens (Fig. 1). Furthermore, the expression levels of BDNF, VEGF and CD105 in SCC tissues were higher than those in normal cervical tissues $(\mathrm{P}<0.001, \mathrm{P}<0.05$ and $\mathrm{P}<0.05$, respectively). However, the expression levels of TrkB in SCC tissues and normal tissues were not significantly different $(\mathrm{P}>0.05$; Table $\mathrm{SII})$.

Association of the expression of BDNF, TrkB and VEGF, as well as MVD, with clinicopathological parameters of the IB2-stage SCC patients. The correlation of the expression levels of BDNF, TrkB and VEGF, as well as the MVD (CD105 positivity), with various clinical indexes was statistically analyzed. The expression of BDNF was significantly correlated with positive LVSI $(\mathrm{P}<0.001)$, pelvic lymph node metastasis $(\mathrm{P}<0.05)$ and exogenous gross type $(\mathrm{P}<0.05)$. Furthermore, the expression of VEGF was associated with larger tumor 

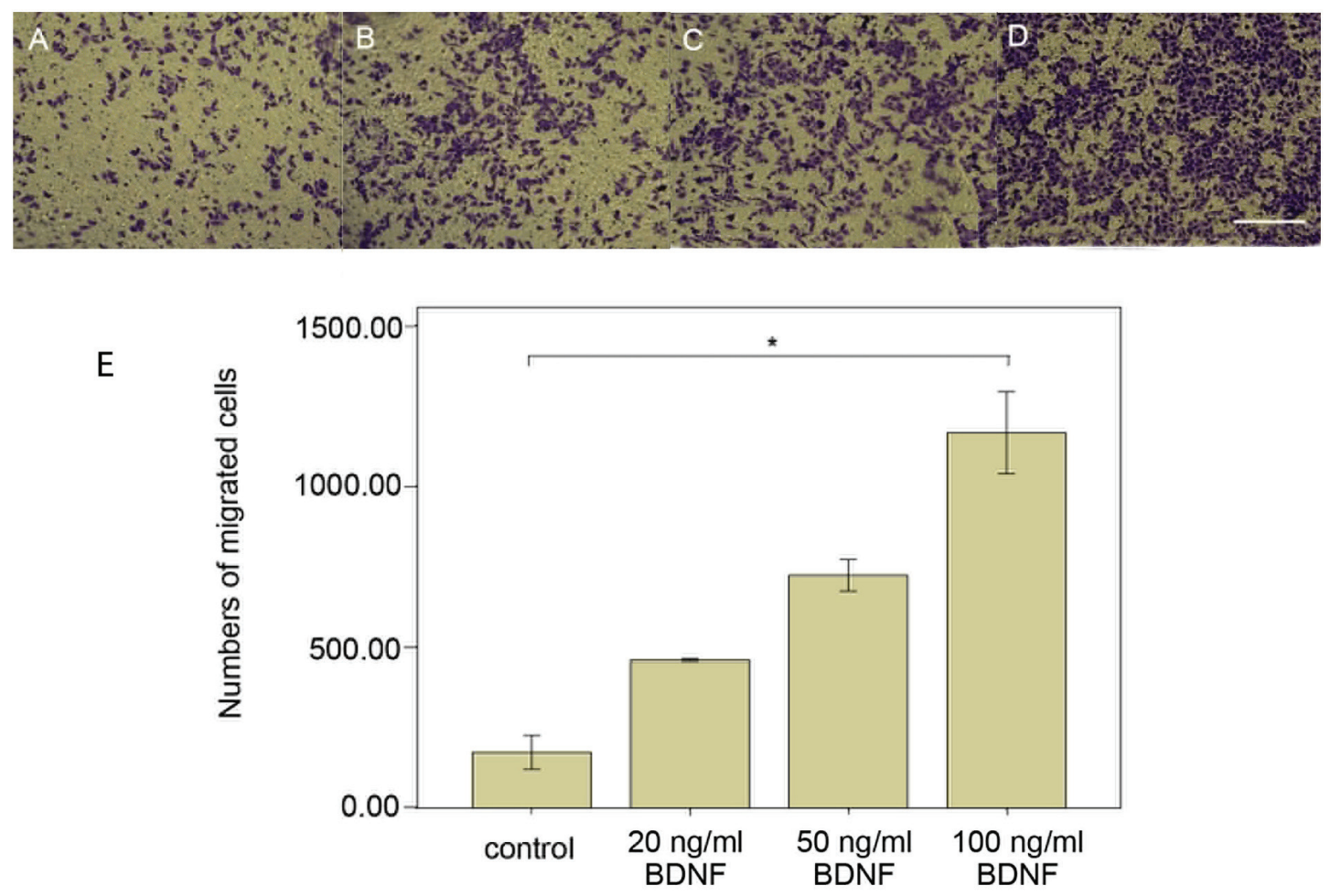

Figure 3. Transwell cellular migration assay using SiHa cells. Starved SiHa cells were (A) treated with PBS or stimulated with BDNF at (B) 20 , (C) 50 or (D) $100 \mu \mathrm{g} / \mathrm{ml}$ for $18 \mathrm{~h}$. Subsequently, the cells were subjected to a Transwell cellular migrative assay, the migrated cells on the filters were stained and representative images are provided in the left-hand panel (scale bar, $1 \mathrm{~mm}$ ). (E) The average numbers of migrated cells in each group (three assays) are provided in a graph. BDNF significantly promoted cellular migration of SiHa cells in a dose-dependent manner. The $100 \mathrm{ng} / \mathrm{ml}$ of BDNF group is most effective among the $20,50$ and $100 \mathrm{ng} / \mathrm{ml}$ of BDNF groups. "P<0.001, BDNF (100 $\mu \mathrm{g} / \mathrm{ml})$ group vs. control group. BDNF, brain-derived neurotrophic factor.
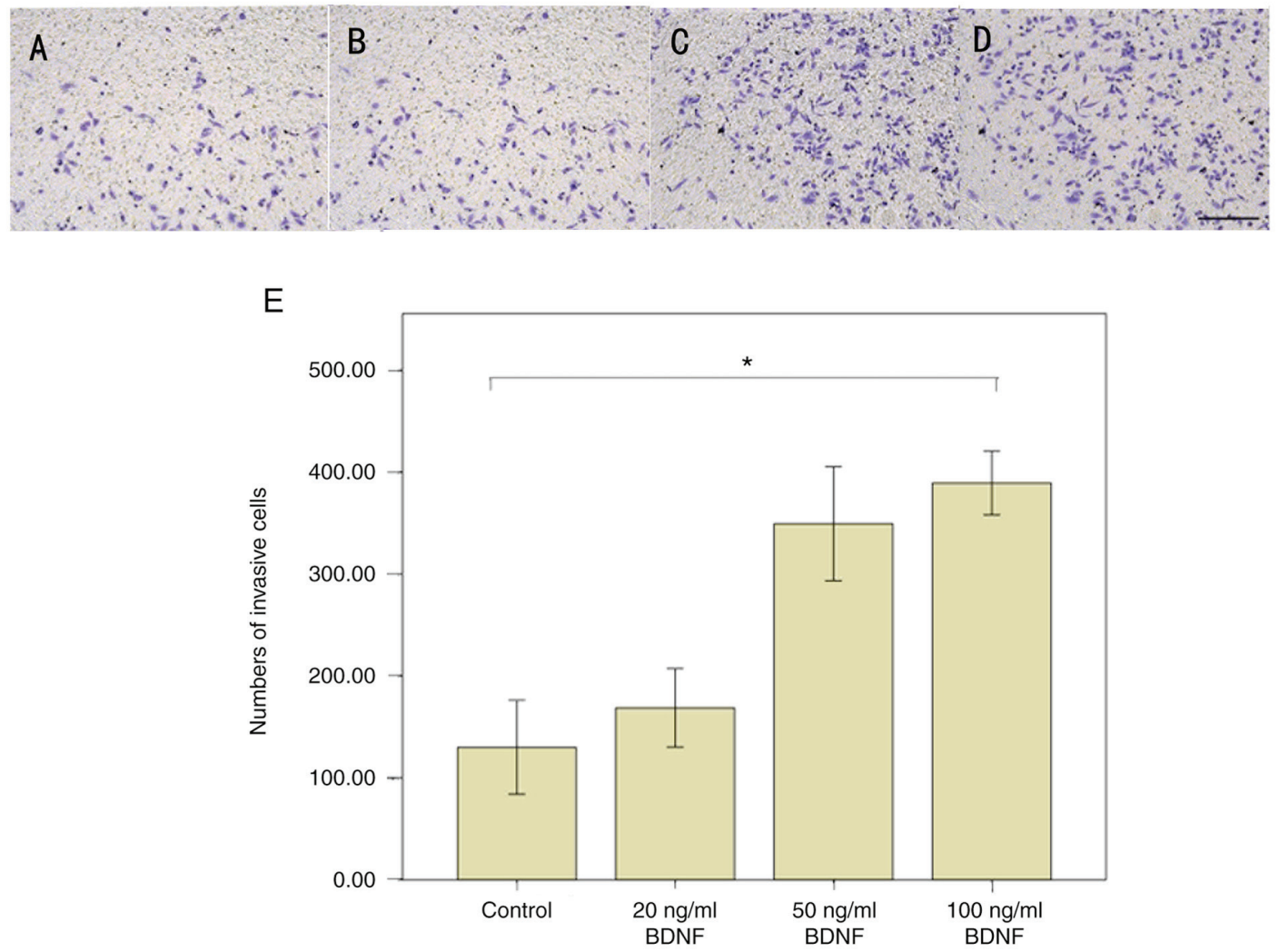

Figure 4. Transwell cellular invasion assay using SiHa cells. Starved SiHa cells were (A) treated with PBS or stimulated with BDNF at (B) 20 , (C) 50 or (D) $100 \mu \mathrm{g} / \mathrm{ml}$ for $18 \mathrm{~h}$. Subsequently, the cells were subjected to a Transwell cellular invasion assay, the invaded cells on the filters were stained and representative images are provided in the left-hand panel (scale bar, $1 \mathrm{~mm}$ ). (E) The average numbers of invaded cells in each group (three assays) are provided in a graph. BDNF significantly promoted cellular invasion of SiHa cells in a dose-dependent manner. The $100 \mathrm{ng} / \mathrm{ml}$ of BDNF group is most effective among the 20,50 and $100 \mathrm{ng} / \mathrm{ml}$ of BDNF groups. ${ }^{*} \mathrm{P}<0.001, \mathrm{BDNF}(100 \mu \mathrm{g} / \mathrm{ml})$ group vs. control group. BDNF, brain-derived neurotrophic factor. 
A

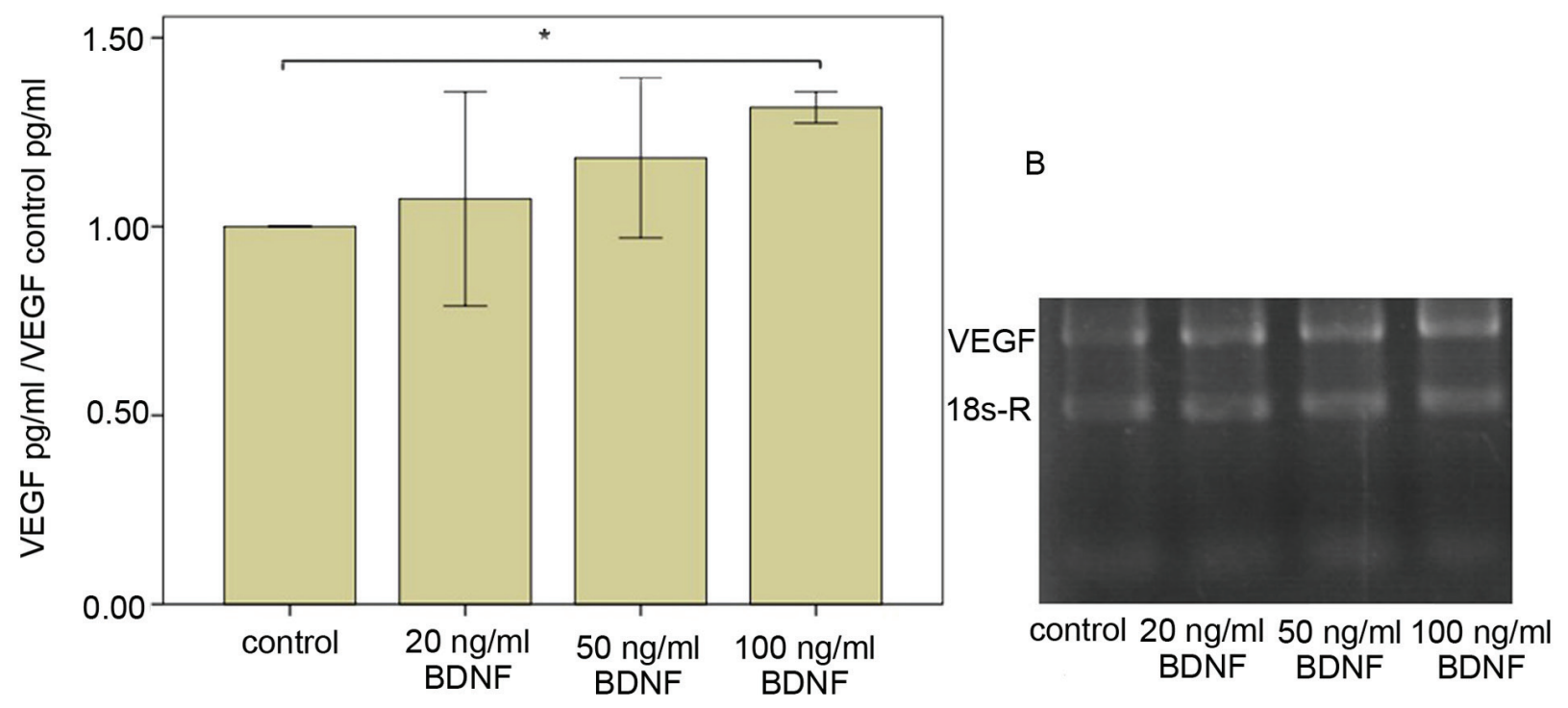

C

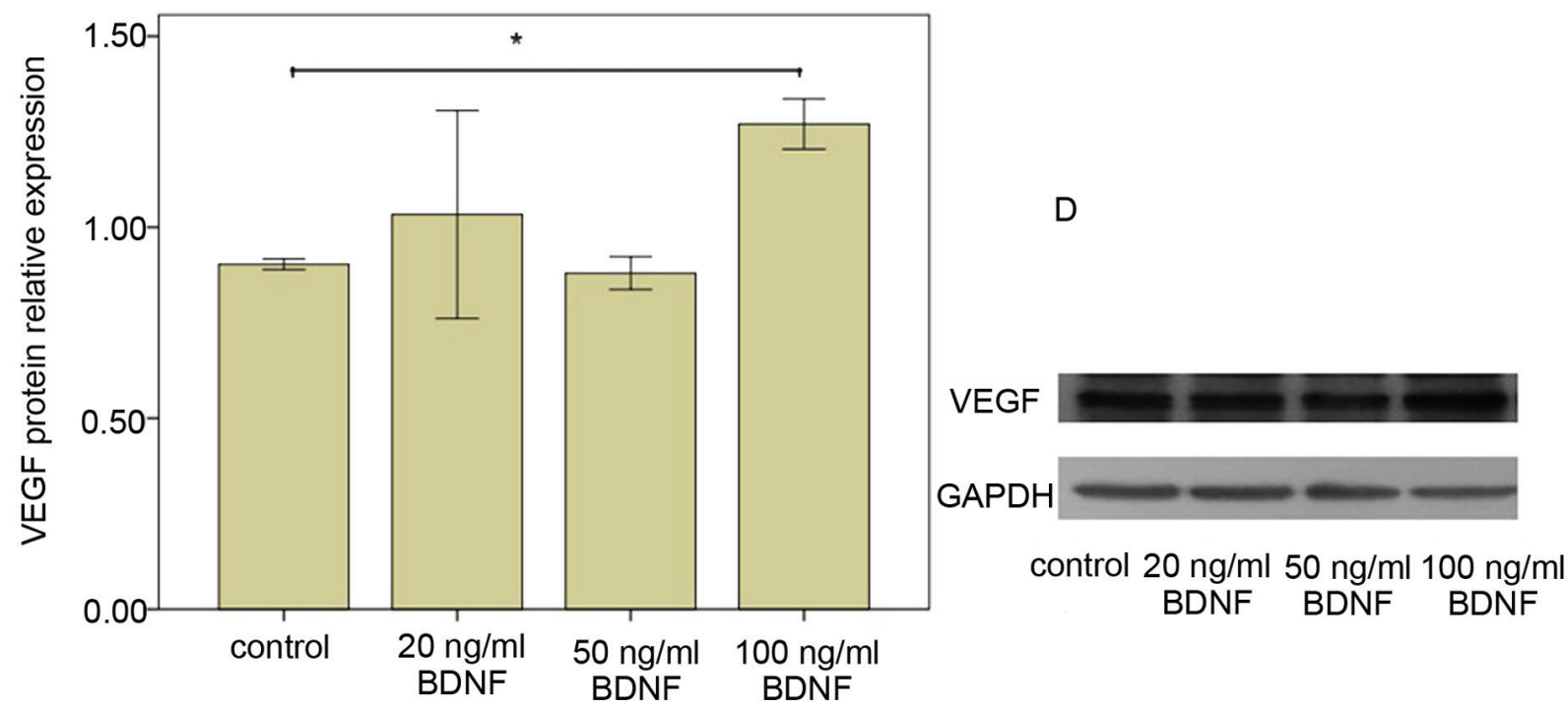

Figure 5. BDNF induces VEGF mRNA and protein expression in SiHa cells. SiHa cells stimulated with the indicated concentrations of BDNF. VEGF-A mRNA levels were detected by reverse transcription semi-quantitative PCR. The maximal expression of VEGF-A was detected in the cells treated with $100 \mathrm{ng} / \mathrm{ml} \mathrm{BDNF}(\mathrm{P}<0.05)$. (A) The average densitometric value for each condition is presented and a (B) representative gel with the PCR amplicons. The protein levels of VEGF were analyzed by western blotting. The maximal expression of VEGF-A was detected in the $100 \mathrm{ng} / \mathrm{ml} \mathrm{BDNF}$-treated cells $(\mathrm{P}<0.05)$. (C) The average densitometric value of the VEGF-A protein for each assay condition and (D) representative bands are presented. Values are expressed as the mean \pm the standard error of the mean from three independent assays. BDNF stimulation of SiHa cells enhanced VEGF-A expression significantly in the protein and RNA level. ${ }^{*} \mathrm{P}<0.05$, BDNF $(100 \mu \mathrm{g} / \mathrm{ml})$ group vs. control group. VEGF, vascular endothelial growth factor; BDNF, brain-derived neurotrophic factor.

size $(\mathrm{P}<0.05)$ and positive LVSI $(\mathrm{P}<0.05)$. No statistically significant correlation was identified between the expression of BDNF, TrkB and VEGF, as well as the MVD (estimated by CD105 stain), and other clinicopathological parameters, including age and DSI ( $\mathrm{P}>0.05$; Tables I and II).

High MVD is an independent predictor of poor prognosis in IB2-stage SCC patients. Among the 79 SCC patients, 23 patients died as the consequence of cervical cancer in the follow-up time of 13 years; the 5-year overall survival
(OS) rate of the SCC patients was $70.9 \%$. According to the univariate analysis of the association of factors with survival, age $>35$ years, as well as higher expression of VEGF and MVD were associated with a poorer prognosis regarding OS $(\mathrm{P}<0.05$; Tables SIII and SIV). However, Cox multivariate regression analysis revealed that only high MVD was an independent prognostic factor for OS (hazard ratio, 2.723; 95\% CI: 1.097-6.762; $\mathrm{P}<0.05$; Fig. 2; Table SV), the expression of $\mathrm{BDNF}$ and VEGF were not independent prognostic factors for OS in SCC patients $(\mathrm{P}>0.05)$. 
A

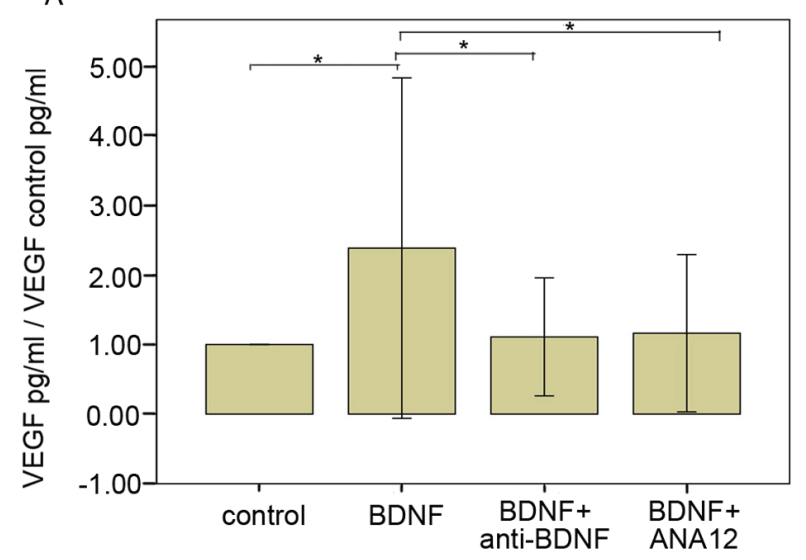

B

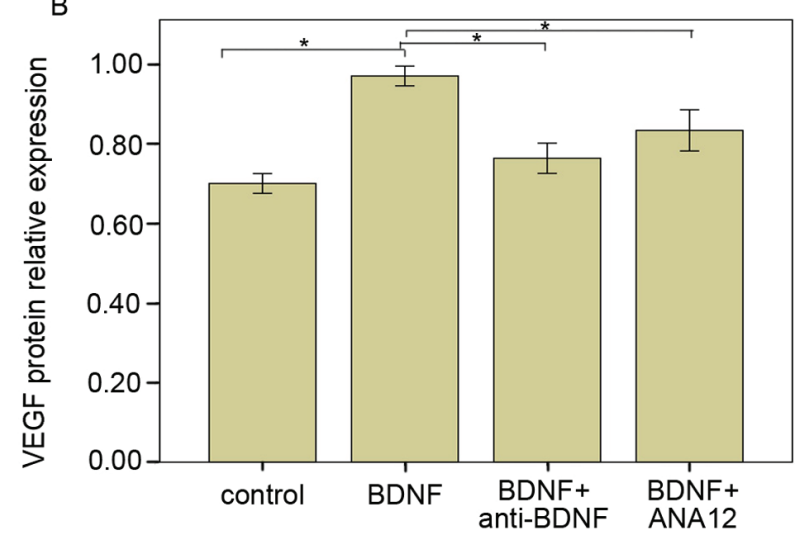

Figure 6. BDNF antibodies or BDNF antagonist ANA12 prevent BDNF-induced VEGF-A expression. BDNF antibodies (BDNF + BDNF antibody) or TrkB antagonist ANA12 (BDNF + ANA12) significantly prevented the $100 \mathrm{ng} / \mathrm{ml}$ BDNF-induced (A) VEGF mRNA and (B) VEGF protein expression $(\mathrm{P}<0.05)$. Values are expressed as the mean \pm the standard error of the mean from three independent assays. ${ }^{*} \mathrm{P}<0.05$. VEGF, vascular endothelial growth factor; BDNF, brain-derived neurotrophic factor; TrkB, tropomyosin receptor kinase $\mathrm{B}$.

BDNF enhances the cellular migratory and invasive potential of SiHa cells. The above results indicated that BDNF is closely linked to the invasive metastatic ability of SCC cells. Therefore, the effect of BDNF on the cellular migratory and invasive abilities of the SiHa cell line was assessed by using Transwell assays. The results indicated that BDNF significantly promoted cellular migration (Fig. 3) and invasion (Fig. 4) of $\mathrm{SiHa}$ cells in a dose-dependent manner. The maximal effective dose was $100 \mathrm{ng} / \mathrm{ml}$ BDNF in the two assays among the 20,50, and $100 \mathrm{ng} / \mathrm{ml} \mathrm{BDNF}$ groups $(\mathrm{P}<0.001)$.

Effect of BDNF-TrkB pathway on VEGF-A regulation. It was indicated that exogenous BDNF stimulation of SiHa cells enhanced VEGF-A protein expression. This response reached a maximum when the concentration of BDNF was $100 \mathrm{ng} / \mathrm{ml}$ $(\mathrm{P}<0.05)$. Furthermore, a similar trend was observed regarding the mRNA expression of VEGF-A ( $\mathrm{P}<0.05$; Fig. 5).

Addition of anti-BDNF antibody or inhibitor of tyrosine kinase receptor (ANA12, an inhibitor of TrkB receptors) obviously prevented the BDNF-induced VEGF-A expression in SiHa cells $(\mathrm{P}<0.05)$, indicating that VEGF-A induction by BDNF was mediated through TrkB receptor binding specifically.
Similar results were obtained from the western blot detection of VEGF-A (P<0.05; Fig. 6).

\section{Discussion}

Pelvic lymph node metastasis is thought to be one of the most important sources of metastasis in cervical cancer. According to the National Comprehensive Cancer Network guidelines from 2015, it is a high-risk factor in cervical cancer patients (17).

BDNF reportedly promotes VEGF-C expression in bladder and cervical tumors. VEGF-C was verified to be positively correlated with pelvic lymph node metastasis in cervical cancer $(18,19)$. Lin et al $(20)$ reported that upregulation of BDNF is always accompanied with increased VEGF-C expression. Furthermore, they indicated that BDNF promoted VEGF-C-associated lymphangiogenesis via the mitogen-activated protein kinase kinase/ERK/mTOR signaling pathway, and further induced lymphatic metastasis. These activities were profoundly inhibited by BDNF knockdown in vivo.

In the present study, BDNF, TrkB, VEGF and CD105 expression was analyzed in the tumor samples of 79 patients with IB2-stage SCC of the cervix, and it was revealed that the BDNF level in cervical cancer samples was significantly associated with LVSI, pelvic lymph node metastasis. The ability of BDNF to stimulate aggressive behavior was further verified in vitro via cellular migration and invasion assays. Macdonald et al (21) investigated data from a large database, indicating that positive lymphatic metastasis is a predictor for poor prognosis in cervical cancer, which is negatively associated with the number of nodes involved. According to this previous study, radical hysterectomy and lymphadenectomy is the classic and standardized type of surgery for certain cervical cancer patients. However, Ferrandina et al (22) reported that the pelvic lymph node metastasis rate of locally advanced cervical cancer was only $10.9 \%$, which means that a large proportion of patients with locally advanced cervical cancer without lymph node metastasis underwent unnecessary pelvic lymph node dissection.

The results of the present study indicated that the expression of BDNF is closely linked to positive LVSI and pelvic lymph node metastasis, suggesting that BDNF may be an effective predictor of lymph node metastasis. Furthermore, BDNF may be a useful indicator to accurately determine the status of lymph node metastasis prior to surgery and to facilitate the selection of appropriate candidates for pelvic lymph node dissection.

The results of the present study also revealed that VEGF expression was associated with tumor size and positive LVSI. In addition, MVD was an independent prognostic factor for OS of patients with SCC of the cervix. Indeed, Duff et al (23) reported a similar correlation of MVD (CD105-positive cells) or VEGF with cervical cancer. Barbu et al (24) reported on the upregulation of VEGF and angiogenesis in cervical adenocarcinomas, which was mainly distributed at the invasion front and indicated poor outcome. The results of a mechanistic in vitro experiment of the present study indicated that exogenous BDNF acting on SiHa cells enhanced VEGF-A expression, and this induction may be blocked by BDNF antibodies or an antagonist of its receptor TrkB (25). Therefore, it may be speculated that BDNF promotes neovascularization 
by induction of VEGF-A expression through binding to its high-affinity receptor TrkB, which indirectly contributes to the progression of the tumor. Therefore, most studies have mainly focused on vascular targeting therapies for cervical cancers, including sunitinib, malate and sorafenib (26). In 2014, the US Food and Drug Administration approved bevacizumab for the clinical treatment of cervical cancer (27). However, anti-vascular targeted therapies are usually accompanied by considerable side effects: $40 \%$ of cervical cancer patients who received vascular targeting therapy had complications, including genitourinary tract spasm and thrombotic disorder, and $2.8 \%$ of the patients died as a result (28). An experiment using animal pancreatic cancer xenografts in a study by Zhao et al (29) revealed that TrkB antagonist significantly reduced the volume of xenografts. Based on the present results, anti-BDNF-TrkA treatment combined with anti-VEGF may be a potential strategy for the clinical treatment of cervical cancers.

\section{Acknowledgements}

Not applicable.

\section{Funding}

This study was supported by key projects of the National Science \& Technology Pillar Program during the Twelfth Five-year Plan Period (grant no. 2014BAI05B03), the National Natural Science Foundation of Guangdong, China (grant no. 2015A030311024), the Medical Research Foundation of Guangdong, China (grant no. A2015063) and the Presidential Foundation of Nanfang Hospital of Southern Medical University (grant no. 2015C015).

\section{Availability of data and materials}

The datasets used and/or analyzed during the present study are available from the corresponding author on reasonable request.

\section{Authors' contributions}

YQ and WL contributed to the study design/planning, data collection/entry, data analysis/statistics and data interpretation. YQ contributed to the preparation of the manuscript and literature analysis/search. MH, WW, SK, LC, BL, ZC, $\mathrm{CL}, \mathrm{JH}$ and $\mathrm{XC}$ contributed to the data collection/entry. $\mathrm{CC}$ and PL contributed to the study design/planning, data collection/entry, data interpretation and funds collection. All authors read and approved the final manuscript.

\section{Ethics approval and consent to participate}

This study was part of a retrospective clinical research project based on a multicenter study of cervical cancer in China. It was approved by the Ethics Committee of Nanfang Hospital, Southern Medical University (Guangzhou, China; code: NEEC-2017-135). Written informed consent for the use of specimens for scientific research was provided by all patients included in the current study.

\section{Patients' consent for publication}

Not applicable.

\section{Competing interests}

The authors declare that they have no competing interests.

\section{References}

1. Li S, Hu T, Lv W, Zhou H, Li X, Yang R, Jia Y, Huang K, Chen Z, Wang S, et al: Changes in prevalence and clinical characteristics of cervical cancer in the People's Republic of China: A study of 10,012 cases from a nationwide working group. Oncologist 18: 1101-1107, 2013.

2. Spencer A, Yu L, Guili V, Reynaud F, Ding Y, Ma J, Jullien J, Koubi D, Gauthier E, Cluet D, et al: Nerve growth factor signaling from membrane microdomains to the nucleus: Differential regulation by caveolins. Int J Mol Sci 18: E693, 2017.

3. Chen CL: Qualitative study on the fine structure of the cervical cancer. Chin J Pract Gyneco Obstetr 5: 440-444, 2015 (In Chinese).

4. Liu YL: Expression of brain- derived neurotrophic factor and its low affinity receptor P75 in stage IB1- IIB cervical squamous cell carcinoma and normal cervical tissues. Chin J Pract Gyneco Obstetr 33: 200-204, 2017 (In Chinese)

5. Höfner T, Klein C, Eisen C, Rigo-Watermeier T, Haferkamp A, Trumpp A and Sprick MR: The influence of prostatic anatomy and neurotrophins on basal prostate epithelial progenitor cells. Prostate 76: 114-121, 2016.

6. Johnson MD, Stone B, Thibodeau BJ, Baschnagel AM, Galoforo S, Fortier LE, Ketelsen B, Ahmed S, Kelley Z, Hana A, et al: The significance of Trk receptors in pancreatic cancer. Tumour Biol 39: 1010428317692256, 2017.

7. Noh SJ, Kim KM and Jang KY: Individual and co-expression patterns of nerve growth factor and heme oxygenase-1 predict shorter survival of gastric carcinoma patients. Diagn Pathol 12: 48, 2017.

8. Pundavela J, Roselli S, Faulkner S, Attia J, Scott RJ, Thorne RF, Forbes JF, Bradshaw RA, Walker MM, Jobling $\mathrm{P}$ and Hondermarck H: Nerve fibers infiltrate the tumor microenvironment and are associated with nerve growth factor production and lymph node invasion in breast cancer. Mol Oncol 9: 1626-1635, 2015.

9. Roh J, Muelleman T, Tawfik O and Thomas SM: Perineural growth in head and neck squamous cell carcinoma: A review. Oral Oncol 51: 16-23, 2015.

10. Sakamoto Y, Kitajima Y, Edakuni G, Sasatomi E, Mori M, Kitahara K and Miyazaki K: Expression of Trk tyrosine kinase receptor is a biologic marker for cell proliferation and perineural invasion of human pancreatic ductal adenocarcinoma. Oncol Rep 8: 477-484, 2001.

11. Alouini S, Rida K and Mathevet P: Cervical cancer complicating pregnancy: Implications of laparoscopic lymphadenectomy. Gynecol Oncol 108: 472-477, 2008.

12. Landoni F, Maneo A, Colombo A, Placa F, Milani R, Perego P, Favini G, Ferri L and Mangioni C: Randomised study of radical surgery versus radiotherapy for stage Ib-IIa cervical cancer. Lancet 350: 535-540, 1997.

13. Scambia G, Benedetti Panici P, Foti E, Amoroso M, Salerno G, Ferrandina G, Battaglia F, Greggi S, De Gaetano A and Puglia G: Squamous cell carcinoma antigen: prognostic significance and role in the monitoring of neoadjuvant chemotherapy response in cervical cancer. J Clin Oncol 12: 2309-2316, 1994.

14. Weidner N: Chapter 14. Measuring intratumoral microvessel density. Methods Enzymol 444: 305-323, 2008.

15. Mohammadi P, Saidijam M, Kaki A, Etemadi K, Shabab N and Yadegarazari R: A pilot study of CK19, CK20 and GCC mRNA in the peripheral blood as a colorectal cancer biomarker panel. Int J Mol Cell Med 5: 30-36,2016.

16. Livak KJ and Schmittgen TD: Analysis of relative gene expression data using real-time quantitative PCR and the 2(-Delta Delta C(T)) method. Methods 25: 402-408, 2001.

17. Koh WJ, Greer BE, Abu-Rustum NR, Apte SM, Campos SM, Cho KR, Chu C, Cohn D, Crispens MA, Dorigo O, et al: Cervical cancer, version 2.2015. J Natl Compr Canc Netw 13: 395-404, 2015.

18. Dai Y, Tong R, Guo H, Yu T and Wang C: Association of CXCR4, CCR7, VEGF-C and VEGF-D expression with lymph node metastasis in patients with cervical cancer. Eur J Obstet Gynecol Reprod Biol 214: 178-183, 2017. 
19. Kawamoto M, Onishi H, Ozono K, Yamasaki A, Imaizumi A Kamakura S, Nakano K, Oda Y, Sumimoto H and Nakamura M: Tropomyosin-related kinase B mediated signaling contributes to the induction of malignant phenotype of gallbladder cancer. Oncotarget 8: 36211-36224, 2017.

20. Lin CY, Wang SW, Chen YL, Chou WY, Lin TY, Chen WC, Yang CY, Liu SC, Hsieh CC, Fong YC, et al: Brain-derived neurotrophic factor promotes VEGF-C-dependent lymphangiogenesis by suppressing miR-624-3p in human chondrosarcoma cells. Cell Death Dis 8: e2964, 2017.

21. Macdonald OK, Chen J, Dodson M, Lee CM and Gaffney DK: Prognostic significance of histology and positive lymph node involvement following radical hysterectomy in carcinoma of the cervix. Am J Clin Oncol 32: 411-416, 2009.

22. Ferrandina G, Distefano M, Mascilini F, Gallotta V, Chiantera V, Cosentino F, Costantini B, Ercoli A, Pedone Anchora L, Fanfani F, et al: Could lymphadenectomy be avoided in locally advanced cervical cancer patients administered preoperative chemoradiation? A large-scale retrospective study. Eur J Surg Oncol 43: 2270-2276, 2017.

23. Duff SE, Li C, Garland JM and Kumar S: CD105 is important for angiogenesis: Evidence and potential applications. FASEB J 17: 984-992, 2003

24. Barbu I, Craitoiu S, Simionescu CE, Dragnei AM and Margaritescu C: CD105 microvessels density, VEGF,EGFR-1 and c-erbB-2 and their prognostic correlation in different subtypes of cervical adenocarcinoma. Rom J Morphol Embryol 54: 519-530, 2013.

25. Zhang J, Liu J, Zhu C, He J, Chen J, Liang Y, Yang F, Wu X and Ma X: Prognostic role of vascular endothelial growth factor in cervical cancer: A meta-analysis. Oncotarget 8: 24797-24803, 2017.
26. Godoy-Ortiz A, Plata Y, Alcaide J, Galeote A, Pajares B, Saez E, Alba E and Sánchez-Muñoz A: Bevacizumab for recurrent, persistent or advanced cervical cancer: Reproducibility of GOG 240 study results in 'real world' patients. Clin Transl Oncol 20: 922-927, 2018.

27. Penson RT, Huang HQ, Wenzel LB, Monk BJ, Stockman S, Long HJ III, Ramondetta LM, Landrum LM, Oaknin A, Reid TJ, et al: Bevacizumab for advanced cervical cancer: Patient-reported outcomes of a randomised, phase 3 trial (NRG Oncology-Gynecologic Oncology Group protocol 240). Lancet Oncol 16: 301-311, 2015 .

28. Sturdza A, Hofmann S, Kranawetter M, Polterauer S, Grimm C, Krainer M, Kirisits C, Pötter R, Reinthaller A and Schwameis R: Increased genitourinary fistula rate after bevacizumab in recurrent cervical cancer patients initially treated with definitive radiochemotherapy and image-guided adaptive brachytherapy. Strahlenther Onkol 193: 1056-1065, 2017.

29. Zhao CM, Hayakawa Y, Kodama Y, Muthupalani S, Westphalen CB, Andersen GT, Flatberg A, Johannessen H, Friedman RA, Renz BW, et al: Denervation suppresses gastric tumorigenesis. Sci Transl Med 6: 250ra115, 2014.

(c) (i) () This work is licensed under a Creative Commons EY NG ND Attribution-NonCommercial-NoDerivatives 4.0 International (CC BY-NC-ND 4.0) License. 